\title{
The effect of Am241 on UK plutonium recycle options in thorium-plutonium fuelled LWRS - Part II: BWRs
}

S. L. Morrison ${ }^{1}$, and G. T. Parks ${ }^{2}$

\author{
${ }^{1}$ University of Cambridge: Engineering Department, Trumpington Street, Cambridge, CB2 1PZ. \\ slm85@cam.ac.uk \\ ${ }^{2}$ University of Cambridge: Engineering Department, Trumpington Street, Cambridge, CB2 1PZ. \\ gtp10@cam.ac.uk
}

Keywords: Thorium, plutonium, americium, disposition, spatial separation, BWR, VC

\begin{abstract}
UK plutonium is expected to be managed using uranium-plutonium (U-Pu) mixed oxide (MOX) fuels in Light Water Reactors (LWRs). However, studies have shown that thorium-plutonium (Th-Pu) may be preferential. Part I of this study considered the effect of americium (Am) in UK Pu in Pressurized Water Reactors (PWRs) and found that, while the reactivity response was sensitive to isotopic and spectral variations, trends were predictable. Part II focusses on separation of Am in Boiling Water Reactors (BWRs) and compares fuel performance to the uniformly distributed and spatially separated cases outlined in Part I. Comparable incineration rates are achievable but, while a single PWR assembly bears a greater mass of Am/Pu than a single BWR assembly, the full BWR core may be capable of operating with significantly greater fissile masses. Transmutation of Am241 to Am242 appears preferable to fast fission of Am241 as increased incineration occurs in lower void, bottom-of-assembly locations.
\end{abstract}

\section{Introduction}

While a decision has yet to be made concerning long-term disposal or disposition of the UK plutonium (Pu) stockpile, a number of potential options may warrant further consideration if they are to aid in guiding the direction and outcome of the decision-making process. If a recycle strategy is pursued, it is expected that this will focus on the use of mixed oxide (MOX) fuels in thermal reactors - most likely Light Water Reactors (LWRs) given the current build proposals and projects underway in the UK. Thorium may offer certain advantages, outlined in Part I of this study, making it a viable alternative to uranium.

Though the objective of a potential recycle strategy is not yet clear, it will likely focus on reducing the stockpile as quickly as possible, i.e. single pass recycle, or may aim to move towards closing the fuel cycle completely, i.e. multiple pass recycle. Regardless of which route may be pursued, it is reasonable to assume that any recycle strategy sought may involve incineration of Am241 in situ. Significant quantities have built up through years of decay of Pu241, such that $\sim 4 \%$ wt of the total mass of the stockpile is Am241, equating to 4 tonnes (Gill, 2016). Although Am may be further separated from $\mathrm{Pu}$, it is unlikely that an additional reprocessing strategy would be included unless there was a strong economic incentive (e.g. if it was lucrative to separate and sell Am for radioisotope thermoelectric generators for the space program) or it was deemed infeasible to recycle UK Pu with Am present due 
to fuel performance or safety related concerns. Part I of this study focuses on the effect of the presence and concentration of Am on UK Pu performance in Pressurized Water Reactors (PWRs) while Part II will focus on Boiling Water Reactors (BWRs).

\subsection{Transuranic (TRU) waste recycle in BWRs}

As with PWRs, it has been shown that Th-Pu MOX fuelled BWRs are viable options for existing as well as advanced designs (Humphrey \& Khandaker, 2018) (Seifried, et al., 2015) (Ganda, et al., 2012). The harder spectrum of the BWR lends itself well to use with Th-fuels, because the higher conversion ratio of Th232 compared to U238 leads to lower fissile loading requirements to achieve a given discharge burnup when compared to U-MOX options. The lower fissile loading requirements result in a more favourable void coefficient (Kim \& Downar, 2002).

For single stage recycle, 'clean' reactor grade Pu from spent LWR fuel performs favourably in Thfuelled BWRs, with neutronic parameters such as reactivity coefficients and control rod worth being similar to those of standard low enriched $U$ and U-Pu MOX fuels, provided that the initial Pu vector does not include separated U233 (Insulander Bjork, et al., 2011). Increasing the hydrogen-to-heavymetal $(\mathrm{H} / \mathrm{HM})$ ratio improves Pu loading efficiency and incineration potential and allows for a $20 \%$ increase in energy that can be extracted from a given amount of Pu. However, the deeper burn of $\mathrm{Pu}$ results in the discharged Pu being of very low fissile quality, which would almost certainly rule out further recycles (Insulander Bjork, 2013).

For multiple stage recycle schemes, assembly-level calculations have shown that reduced moderation BWRs (RBWRs) typically result in lower levels of minor actinides (MAs) in discharged fuel than reduced moderation PWRs (RMPWRs), because the tight pitch and relatively high void fraction in the RBWR leads to a greater reduction in moderation and, consequently, a harder spectrum, reducing breeding of and increasing the fission rate in these isotopes (Lindley, et al., 2014a). This leads to lower reload requirements for each stage of recycle, ultimately resulting in more favourable reactivity feedback coefficients. However, the harder spectrum also causes reduced incineration rates relative to the RMPWR, due to the higher conversion ratio in the RBWR and competing effects in fissile and fissionable isotopes. Despite this, significantly higher burnups appear to be achievable in the RBWR than the RMPWR. In fact, cladding technology imposes burnup limits rather than the fuel or reactor type. Further, full-core analysis of the RBWR has shown that the discharge burnup achievable may be even higher than predicted in the assembly-level calculations, due to the relative influences of high and low void fraction (VF) regions in the core. However, it should be noted that there may be some uncertainty in the core Void Coefficient (VC) as a result of sensitivity to calculation method, and, therefore, a margin of error may be required to mitigate this (Lindley, et al., 2014a) (Lindley, et al., 2014b). Homogeneously loaded fuel was found to result in excellent burnup potential in the RBWR, while heterogeneously loaded fuel - radial separation of Th-U233 and Th-TRU in the form of TCUP assembly designs and checkboard loading patterns - was found to be neutronically extremely effective. Separation was determined to offer significant improvements in the VC, which allowed substantially increased reload enrichments. Depending on how the MAs were separated, extremely high burnups - comparable to those obtained in Fast Reactors - were found to be achievable (Lindley, et al., 2014c). 


\subsection{Effect of Am on performance}

With regard to Am-only transmutation, many studies have focused on spatial separation of Am in BWRs; however, these have been mostly limited to U-fuels (Raitses, et al., 2005). Various assemblylevel studies have considered different options for ideal placement of Am with the intention of exploiting softer and harder spectrum regions of the BWR. Replacing Gd with Am241 in typically Gdbearing pin locations with the intention of using Am as a burnable absorber (BA) has been considered (Erighin, et al., 2006) (Francois \& Guzman, 2007). The large thermal capture cross section of Am241 was shown to result in suppression of initial reactivity; however, the through-life behaviour of Ambearing pins should be carefully assessed since capture in Am241 produces Am242g and Am242m, both of which have a large thermal fission cross section. (Erighin, et al., 2006) considered 7\%wt Am in previously-Gd-bearing pins in a top-of-core assembly and found that a decrease of $\sim 50 \%$ of the total mass inventory of Am was achievable. The BA behaviour of Am in 5 and 10\%wt Am cases was also studied and results showed that the infinite multiplication factor (kinf) versus burnup curves of Ambearing pins displayed notable differences to Gd-bearing pins. Am-bearing pins were found to deplete at a more uniform rate throughout the cycle. Interestingly, the study found that placing Am in high void locations did not necessarily result in increased burning of Am compared with placing it in low void locations. This suggests that thermal transmutation of Am241 to Am242g and Am242m may be preferable compared to targeting increased fast fission in Am241. However, these results may be specific to U-based fuels only, as the study predicted that burning potential may be limited by competing effects caused by the production of fissile Pu239 and Pu241. (Wallenius \& Westlen, 2008) focused on targeting fast fission in Am241 and considered MA recycle (with 6\%wt Am) in a faster spectrum, top-of-assembly location with $\mathrm{Hf}$ cladding to harden the spectrum further. The study determined that a small net destruction was possible. Further studies have considered placing MAs (including 4\%wt Am241) in all pins within the assembly with varying total fissile enrichments such that adequate shutdown margins (SDMs) could be achieved for the desired cycle length (Francois, et al., 2011). This was found to be feasible, but an optimisation study was required to ensure burning potential was maximised.

Full-core studies have yielded similarly positive results with regard to spatial separation of Am. (Maldonado, et al., 2010) considered optimising a core loading pattern to maximise Am incineration in $\mathrm{UO}_{2}$ pins spiked with 3\% Am241. 2D lattice models were individually optimised to determine the ideal location for Am-bearing pins and these were 'stacked' axially to make up a full 3D core with 4 axial zones: upper and lower uranium blankets, a lower 'dominant' zone including partial length rods and an upper 'vanishing' zone. Results showed that, with axial zoning, up to $90 \%$ of the loaded Am could be incinerated for burnups of $60-80 \mathrm{GWd} / \mathrm{tHM}$, and optimisation of the Am location within the fuel bundles improved transmutation by $\sim 3 \%$ by the end of the first cycle. (Ramirez, et al., 2016) considered radial-only zoning of MAs in a full core such that 4 pins in each assembly contained $\sim 6 \% \mathrm{wt}$ MAs with $U$ enrichment varied to achieve the same kinf behavior as the $\mathrm{UO}_{2}$ reference case. Axial zoning was accounted for, but this only applied to $\mathrm{UO}_{2}$ enrichment, while MA content remained constant. Safety parameters, such as VC, SDM and peaking factors, were shown to worsen through the addition of MAs but remained within safe bounds, and a reduction in the total MA inventory was found to be possible.

Overall, Th-MOX studies appear to suggest that radial separation of MAs would be neutronically advantageous; however, less is known about the potential benefits of axial separation of Am in Th- 
MOX. U-MOX results indicate that there may be benefits in pursuing axial separation, but the potential for Am burning in the absence of a Pu breeding environment has yet to be determined. Therefore, this study will primarily focus on axial separation of Am in Th-Pu MOX fuel. Since it is not clear from these studies whether upper or lower assembly positions would provide a better platform for Am transmutation in Th-Pu systems, both options will be considered. Before assessing the benefits of axial separation, an initial flux comparison will be carried out to determine whether the trends identified in Part I of this study regarding the sensitivity and likely response of reactivity feedback coefficients to changes in isotopic composition of the fuel and spectral effects may be applied to Th-Pu MOX fuels in BWRs as well as PWRs and RMPWRs. If the spectrum is similar to those previously considered, similarly predictable trends may be assumed.

\section{Method}

\subsection{Pu vectors and model set-up}

As per Part I of this study, different UK Pu vectors have been considered, based on the predicted UK Pu vector (Gill, 2016), and have been scaled in line with increasing Am content. This study will be based around an assumed single-pass recycle in a GE Hitachi style ABWR (Hitachi-GE Nuclear Energy Ltd, 2017). This reactor design was chosen as it has been the main focus of the proposed UK BWR build. The Pu vectors detailed in Table 1 once again consider three bounding cases for the UK Pu stockpile based on a single lumped mass Pu vector:

1. Recently reprocessed, and therefore isotopically 'clean', Pu (0\%wt Am),

2. Isotopically averaged 'as is' Pu (3.91\%wt Am), and

3. Aged Pu, where all Pu241 has decayed to Am241 (5.60\%wt Am).

Table 1 Isotopic composition of plutonium vectors

\begin{tabular}{llllllll}
\hline \multicolumn{7}{c}{$\begin{array}{l}\text { Am } \\
\text { content }\end{array}$} & \multicolumn{6}{l}{ Isotopic composition (\%wt) } & & & \\
& (\%wt) & Pu238 & Pu239 & Pu240 & Pu241 & Pu242 & Am241 \\
\hline Clean & 0.00 & 0.2498 & 68.7689 & 26.7041 & 1.7588 & 2.5185 & 0.0000 \\
As is & 3.91 & 0.2400 & 66.0800 & 25.6600 & 1.6900 & 2.4200 & 3.9100 \\
Aged & 5.60 & 0.2400 & 66.0800 & 25.6600 & 0.0000 & 2.4200 & 5.6000 \\
\hline
\end{tabular}

Before results were gathered, an initial comparison was carried out using WIMS (Lindley, et al., 2017) (Askew, et al., 1966) and the Monte Carlo code, Serpent (Leppanen, et al., 2015), with nuclear data library ENDF/B-VII (Chadwick, et al., 2006) for a single, two-dimensional, 10x10 bottom-of-core fuel assembly (as described in Table 2). Fuel was assumed to be $4.9 \%$ enriched $\mathrm{UO}_{2}$ with a discharge burnup of $60 \mathrm{GWd} / \mathrm{tHM}$ as per the proposed UK ABWR design. Good agreement was found between the two models (Table 3); however, discrepancies arose when the fuel type was changed from $\mathrm{UO}_{2}$ to $\mathrm{Th}-\mathrm{Pu}$ MOX. This is believed to be due to inadequacies in the sub-group treatment used in WIMS which leads to inaccuracies in modelling advanced BWRs. Serpent was therefore used for the second part of this study. The initial single assembly, two-dimensional model (2D 1FA) was amended to allow results to be recorded for fuel performance in a 4x4, three-dimensional fuel bundle (3D 4FA) (Table 3). Good agreement was found between the 2D and 3D serpent models, though the 2D 1FA model slightly overestimated keff at beginning of cycle (BOC) as it was modelled as being axially infinite, whereas the 3D 4FA modelled a fuel bundle with a fixed height. Nevertheless, the discrepancies between models were deemed to be acceptable and found to be within generally accepted tolerances (Ramirez, et al., 
2016) (O'Donnell, et al., 2001). The 3D model was used for the purposes of calculation since results of previous studies have suggested that 2D models may underestimate certain parameters, for example, the achievable burnup. However, a full 3D core model would be computationally expensive and, since this is primarily a feasibility study, a single assembly was deemed to be appropriate.

The 3D model was separated into six axial zones to account for variations in water density and to allow for axial fuel zoning. The six water densities defined in Table 2 were taken as averages based on the 24 separate axial region water densities quoted in (GE Nuclear Energy, 1997). This was deemed to be an acceptable approximation since there was very little variation in the results when comparing keff calculated with 24 vs. 6 axial water densities, but the CPU time was marginally increased where a greater number of densities was modelled. Partial rods were assumed to extend half way up the assembly (Figure 1). The theoretical densities of $\mathrm{PuO}_{2}$ and $\mathrm{ThO}_{2}$ were assumed to be $11.5 \mathrm{~g} / \mathrm{cc}$ and $10.0 \mathrm{~g} / \mathrm{cc}$ respectively, and, for all fuel materials used, the assumed density was $95 \%$ of the corresponding theoretical density. For purposes of comparison, a number of design constraints were fixed: the assembly linear power rating was assumed to be $12.66 \mathrm{~kW} / \mathrm{cm}$ as per the proposed UK ABWR design; and thrice-burned fuel was expected reach a total discharge burnup of $60 \mathrm{GWd} / \mathrm{tHM}$, similar to the PWR/RMPWR in Part I of this study. For a three-batch fuel management scheme with a discharge burnup of $60 \mathrm{GWd} / \mathrm{tHM}$, keff of 1.03 (or more) was required up to $40 \mathrm{GWd} / \mathrm{tHM}$. This keff value accounts for the effects of neutron leakage, which is typically $3 \%$ in LWRs.

Table 2 Reference assembly geometry and operating conditions

\begin{tabular}{lc}
\hline Parameter & ABWR \\
\hline Fuel pellet radius $(\mathrm{cm})$ & 0.447 \\
Fuel pin radius $(\mathrm{cm})$ & 0.513 \\
Water rod inner radius $(\mathrm{cm})$ & 1.084 \\
Water rod outer radius $(\mathrm{cm})$ & 1.150 \\
Lattice pitch $(\mathrm{cm})$ & 1.295 \\
Active fuel height $(\mathrm{cm})$ & 381 \\
Number of full-length fuel rods & 92 \\
Number of part-length fuel rods & 78 \\
Fuel temperature $(\mathrm{K})$ & 900 \\
Cladding temperature $(\mathrm{K})$ & 600 \\
Moderator temperature $(\mathrm{K})$ & 560 \\
Axial height $(\mathrm{cm})$ & Moderator density $(\mathrm{g} / \mathrm{cc})$ \\
$317.5-381.0$ & 0.2640 \\
$254.0-317.5$ & 0.2918 \\
$190.5-254.0$ & 0.3367 \\
$127.0-190.5$ & 0.4173 \\
$63.5-127.0$ & 0.5829 \\
$0.0-63.5$ & 0.7278 \\
Assembly power $(\mathrm{kW} / \mathrm{cm})$ & 12.66 \\
\hline
\end{tabular}

(Hitachi-GE Nuclear Energy Ltd, 2017) (Radioactive Waste Management Limited , 2016) (Palmtag, 2015) (Gao, 2014) (Nuclear Energy Agency Organisation for Economic Co-operation and Development, 2003) (GE Nuclear Energy, 1997)

Table 3 Benchmark analysis

\begin{tabular}{llll}
\hline Burnup & WIMS & \multicolumn{2}{c}{ Serpent } \\
(GWd/tHM) & 2D 1FA & 2D 1FA & 3D 4FA \\
\hline
\end{tabular}




\begin{tabular}{llll}
\hline 0 & 1.462234 & 1.464040 & 1.458730 \\
60 & 0.838339 & 0.840335 & 0.847434 \\
\hline
\end{tabular}

50,000 neutrons were used to simulate the environment; this choice gave acceptable convergence and statistics within reasonable CPU times. The numbers of active and inactive cycles were also analysed; however, improved statistics are generally obtained by increasing the number of particles rather than these parameters (Kaltiaisenaho, 2014). The number of active and inactive cycles were therefore chosen to be 1000 and 200 respectively, based on the results of the sensitivity study with 50,000 neutrons.

Figure 1 3D BWR assembly showing full and partial rod layout and location

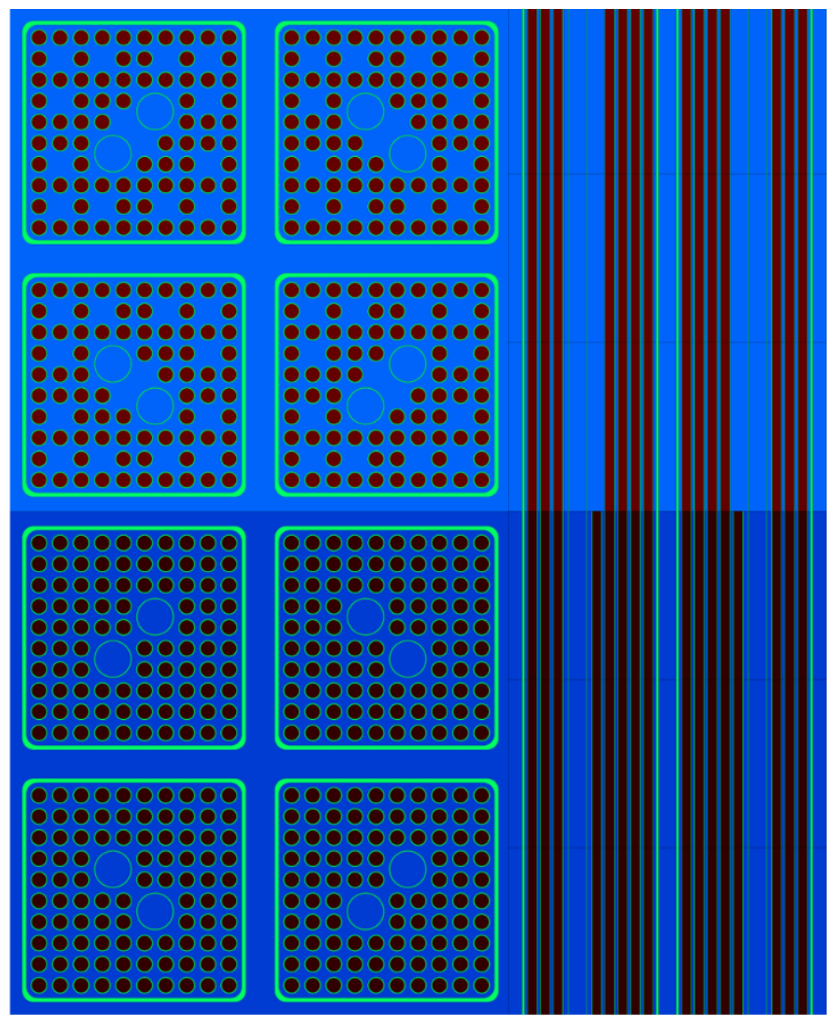

\subsection{Reactivity feedback coefficients}

Changes in reactivity for VC were calculated using Equation 1.

$$
\Delta \rho=\frac{k_{\infty}^{p}-k_{\infty}^{n}}{k_{\infty}^{p} \cdot k_{\infty}^{n}} \frac{1}{\Delta X}
$$

Equation 1

where $n$ and $p$ refer to nominal and perturbed conditions respectively and $X$ represents the \% change in voiding outlined in Table 4. 
Table 4 Perturbed operating conditions

\begin{tabular}{ll}
\hline Coefficient & Perturbation \\
\hline VC (90\% VF) & moderator density reduced to $0.026 \mathrm{~g} / \mathrm{cc}^{1}$ \\
VC (fully voided) & moderator density reduced to $0.001 \mathrm{~g} / \mathrm{cc}^{2}$ \\
\hline
\end{tabular}

\section{Results and discussion}

\subsection{Comparison of ABWR with PWR/RMPWR}

An initial flux comparison was carried out to determine how the spectrum of the ABWR compared to a standard, Sizewell B-type PWR and the more extreme RMPWR from Part I of this study (for UK Pu based Th-Pu fuel containing 30\% Am and 37\% total Pu) (Figure 2). Results show that the spectrum of the ABWR lies somewhere between the PWR and very-hard spectrum RMPWR. Therefore, trends relating to isotopic contributions with increasing Am content can be predicted from the results discussed in Part I of this study, and no "extreme" MTC or VC results should occur for the isotopic compositions considered in this study.

Figure 2 Relative neutron flux for the ABWR and RMPWR compared to the PWR

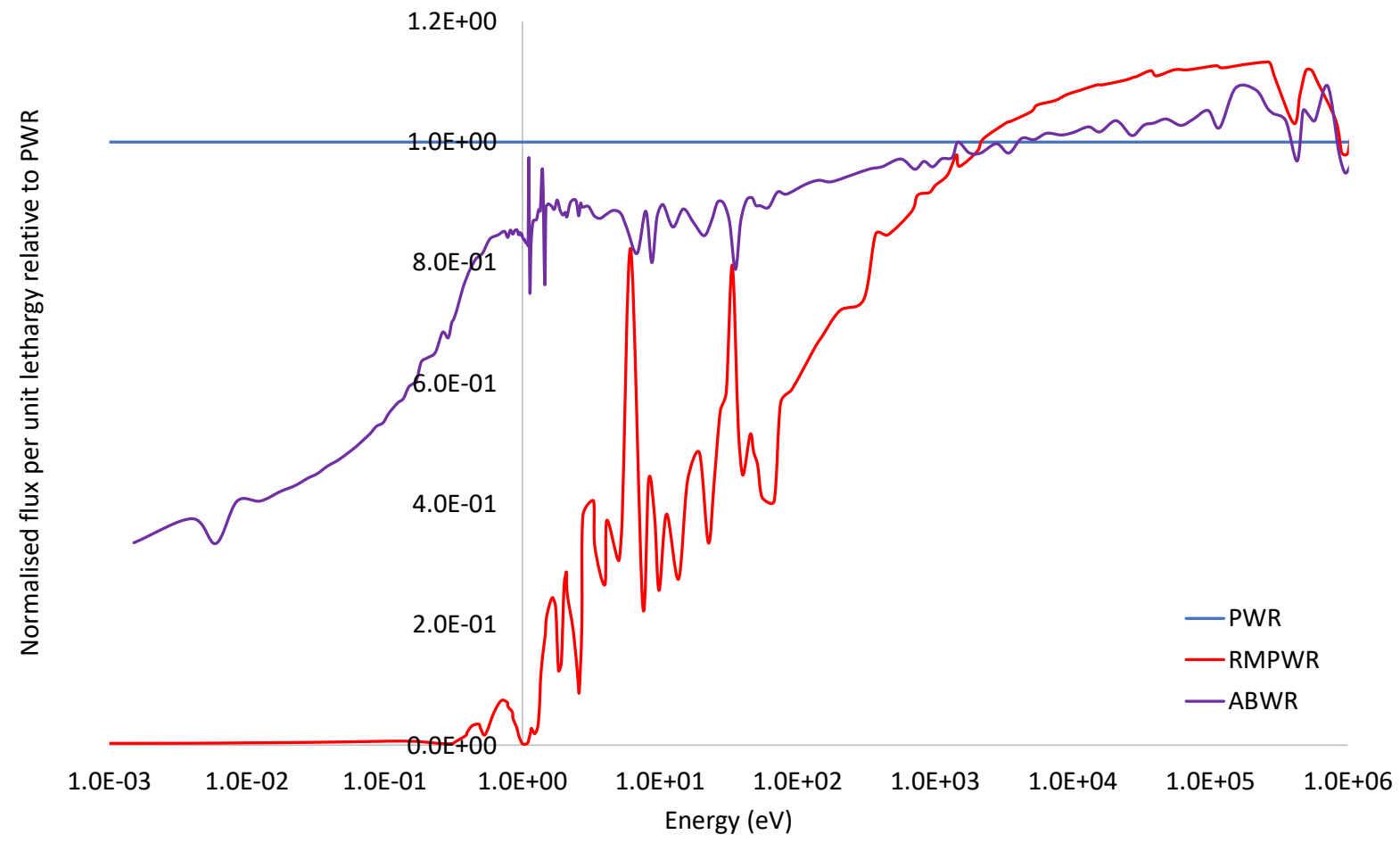

${ }^{1}$ Representing a 90\% VF (top-of-core) as per typically accepted regulatory limits (AREVA/EDF, 2012)

\footnotetext{
2 Representing an extreme LOCA

${ }^{3}$ Refer to Part I of this study
} 


\subsection{Incineration capabilities and effects of spatial separation}

Since the BWR has different axial water densities and different radial degrees of moderation, there are likely to be positions within each assembly that are better suited to Am incineration. Previous studies have shown that there may be merit in placing increased Am in either upper or lower assembly positions for the purposes of increased Am incineration in U-Pu MOX fuels. Since MA burning is typically better suited to faster spectra, the upper part of the assembly may be an ideal location to maximise Am loading within the fuel. However, as previous theorised, Am241 destruction may be best achieved through transmutation to Am242 (ground and meta state) rather than through fission, in which case the lower part of the assembly may be better suited to maximising Am incineration. In order to determine the more favourable location for increased Am content, an initial study was conducted to determine the Pu requirements to achieve keff $=1.03$ at $40 \mathrm{GWd} / \mathrm{tHM}$ for $0,3.91$ and $5.60 \%$ wt Am as per the three bounding cases. The VC was recorded but did not drive the fissile loadings considered; for all three cases, VC was found to be substantially negative.

Once the Pu requirements were determined, the Am content was increased by $1 \%$ in both the upper and lower part of the assembly, while keeping the Pu content fixed. In this case, the discharge burnup was not fixed at $40 \mathrm{GWd} / \mathrm{tHM}$ and the cycle length was allowed to vary slightly so that, for the purposes of comparison, the Pu concentration would remain fixed. Results show that increasing the Am content in the lower half of the assembly resulted in improved Am incineration capability when compared to increasing the Am content in the upper half of the assembly (Table 5). Figure 3 shows the typical flux trend observed for each of the assemblies when comparing the increased Am cases relative to the axially uniform fuel case. This suggests that, when the Am concentration is increased in bottom-of-assembly locations, the absorbing properties of Am241 result in a reduced thermal flux and an increased fast flux. The resultant effect is that there is an increase in breeding of Am242 and of fast fissions in Am241, ultimately leading to an increased amount of destruction of Am. 
Table 5 Effect of increasing Am content in bottom- vs top-of-core locations for the 3 bounding-case Pu vectors ${ }^{4}$

\begin{tabular}{|c|c|c|c|c|c|c|c|c|c|c|}
\hline Parameter & (\%wt) & & Clean & & & As is & & & Aged & \\
\hline Fuel 1 (bottom) & $\mathrm{Am}$ & 0.00 & 0.00 & 1.00 & 3.91 & 3.91 & 4.91 & 5.60 & 5.60 & 6.60 \\
\hline $0-63.5 \mathrm{~cm}$ & $\mathrm{Pu}$ & 12.00 & 12.00 & 12.00 & 13.75 & 13.75 & 13.75 & 15.00 & 15.00 & 15.00 \\
\hline Fuel 2 & $\mathrm{Am}$ & 0.00 & 0.00 & 1.00 & 3.91 & 3.91 & 4.91 & 5.60 & 5.60 & 6.60 \\
\hline $63.5-127 \mathrm{~cm}$ & $\mathrm{Pu}$ & 12.00 & 12.00 & 12.00 & 13.75 & 13.75 & 13.75 & 15.00 & 15.00 & 15.00 \\
\hline Fuel 3 & $\mathrm{Am}$ & 0.00 & 0.00 & 1.00 & 3.91 & 3.91 & 4.91 & 5.60 & 5.60 & 6.60 \\
\hline $127-190.5 \mathrm{~cm}$ & $\mathrm{Pu}$ & 12.00 & 12.00 & 12.00 & 13.75 & 13.75 & 13.75 & 15.00 & 15.00 & 15.00 \\
\hline Fuel 4 & Am & 0.00 & 1.00 & 0.00 & 3.91 & 4.91 & 3.91 & 5.60 & 6.60 & 5.60 \\
\hline $190.5-254 \mathrm{~cm}$ & $\mathrm{Pu}$ & 12.00 & 12.00 & 12.00 & 13.75 & 13.75 & 13.75 & 15.00 & 15.00 & 15.00 \\
\hline Fuel 5 & Am & 0.00 & 1.00 & 0.00 & 3.91 & 4.91 & 3.91 & 5.60 & 6.60 & 5.60 \\
\hline $254-317.5 \mathrm{~cm}$ & $\mathrm{Pu}$ & 12.00 & 12.00 & 12.00 & 13.75 & 13.75 & 13.75 & 15.00 & 15.00 & 15.00 \\
\hline Fuel 6 (top) & Am & 0.00 & 1.00 & 0.00 & 3.91 & 4.91 & 3.91 & 5.60 & 6.60 & 5.60 \\
\hline $317.5-381 \mathrm{~cm}$ & $\mathrm{Pu}$ & 12.00 & 12.00 & 12.00 & 13.75 & 13.75 & 13.75 & 15.00 & 15.00 & 15.00 \\
\hline Pu burned (\%) & & 32.50 & 31.58 & 31.66 & 27.95 & 26.52 & 27.23 & 25.23 & 23.90 & 23.94 \\
\hline Am burned (\%) & & - & -91.93 & -72.99 & 36.82 & 35.69 & 39.68 & 42.00 & 39.64 & 42.67 \\
\hline Burnup (GWd/tHM) & & 40.00 & 39.00 & 39.00 & 40.00 & 38.00 & 39.00 & 40.00 & 38.00 & 38.00 \\
\hline
\end{tabular}

${ }^{4} \mathrm{Pu}$ content was fixed while the discharge burnup was taken to be the burnup (to the nearest $1 \mathrm{GWd} / \mathrm{tHM}$ ) when keff reached $\sim 1.03$ 


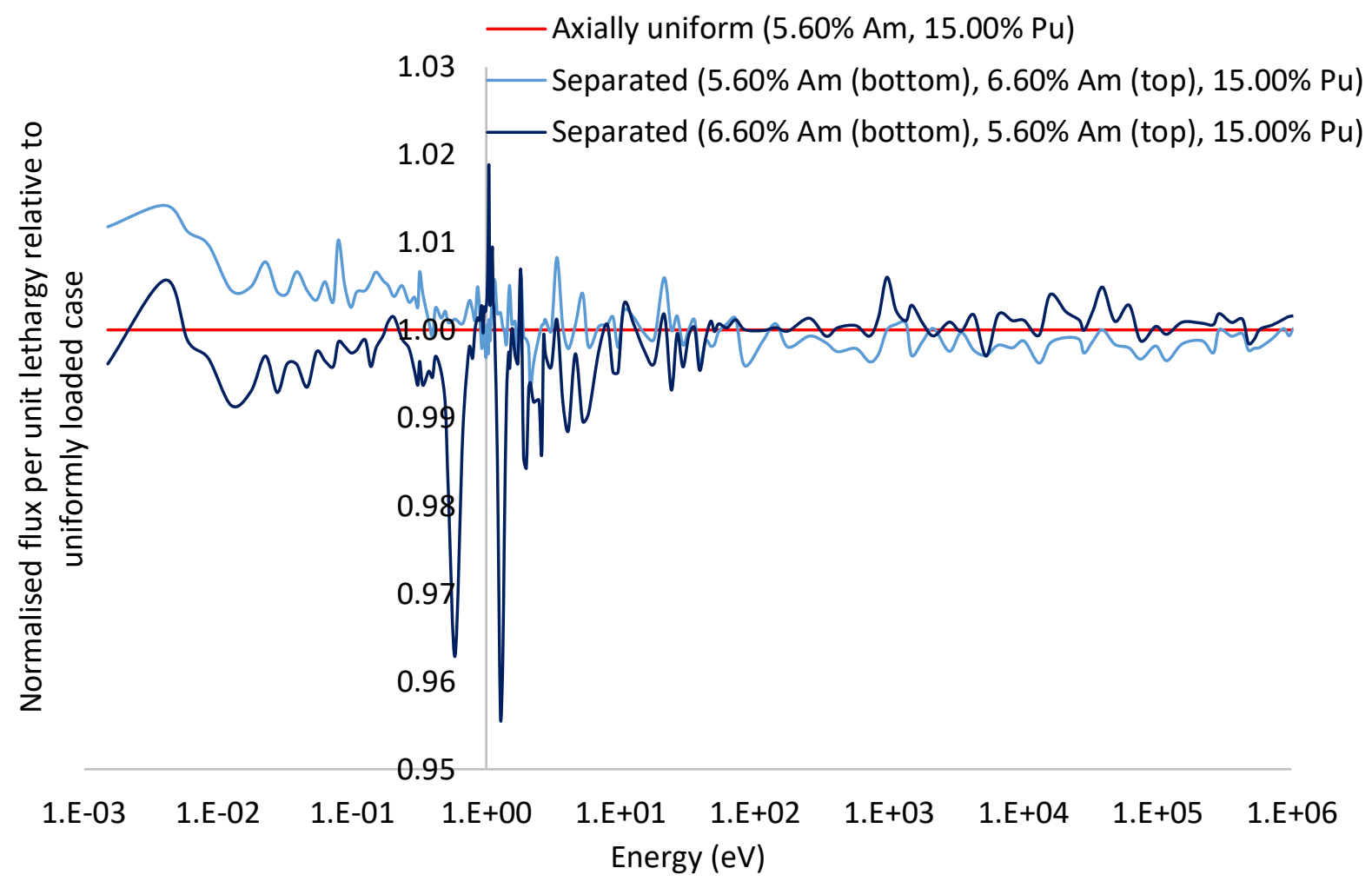

The Am/Pu content was then incremented in the lower part of the assembly, while the fissile content remained fixed in the upper part of the assembly, to the point that VC ( $90 \%$ voided) was only just negative. In the 'clean' Am case, the maximum Am content in the lower part of the assembly was 18\%wt Am/24.75\%wt Pu while the fissile content remained fixed at 0\% Am/12wt Pu in the upper part of the assembly. In the 'as is' and 'aged' cases, the fissile content was $15.91 \% w t$ Am/22.75\%wt Pu in the lower part of the assembly coupled with 3.91\%wt Am/13.75\%wt Pu in the upper part and $15.60 \%$ wt $/ 23.00 \%$ wt Pu in the lower part coupled with 5.60\%wt Am/15.00\%wt Pu in the upper part, respectively. This was deemed to be representative of the VC limited, maximum allowable fissile loading since the $90 \%$ VC would meet the normally imposed regulatory limits even though the fully voided VC may be slightly positive (Table 6).

In some cases, the difference between the Am/Pu content in the upper and lower parts of the assembly is substantial, i.e. $0 \% \mathrm{wt}$ Am (upper) compared to $18 \% \mathrm{wt}$ Am (lower). It may be beneficial to further separate the Am in order to flatten the axial flux profile and, therefore, limit the difference in fuel exposure to neutrons and cladding material to neutron irradiation damage. This was examined by varying the Am content of the upper and lower parts of the assembly about the mid-point of the each of the two regions. Results showed that, in some cases, further axial separation reduced the Am burning efficiency whereas, in others, a small variation in Am content improved the burning efficiency. This apparent anomaly was dictated by the effect of separation on the flux profile and the subsequent effect that this has on the reaction rates within key isotopes. 
The effect is illustrated in the $0 \% /$ clean Am case, where results show that the fission and capture rates for Am241 are higher when Am is not further separated (i.e. $\pm 0 \%$ rather than $\pm \geq 1 \%$ ) (Figure 4 ). Therefore, this option offers the maximum incineration potential of the cases considered. In addition, the capture rate is an order of magnitude greater than the fission rate, which further supports the theory that transmutation to Am242g/m may be a better approach for Am destruction than targeting increased fast fission in Am241. The axial flux profile changes with burnup (Figure 5) and the difference between the \pm 0 and $1 \%$ cases dictates the reaction rates. In low burnup cases, the flux is significantly higher in the upper part of the assembly and is marginally greater in the $\pm 0 \%$ case. Although the fissile content is lower in the upper part of the assembly, the increased flux results in a greater burning potential in the $\pm 0 \%$ case in this region. As the cycle progress, such as at $20 \mathrm{GWd} / \mathrm{tHM}$ burnup (BU), the flux profile flattens, and the flux in the upper part of the assembly is greater in the $\pm 1 \%$ case. However, in this case, the flux profile along the assembly is flatter and, given that the Am content in the lower part of the assembly is significantly higher and the flux is higher in the $\pm 0 \%$ case, the Am destruction rate remains greater in the $\pm 0 \%$ case. By end of cycle (EOC), the flux profile has shifted such that the flux is notably higher in the lower part of the assembly compared to the upper part and, as with $\mathrm{MOC}$, the flux is higher in the $\pm 0 \%$ case, which again results in a greater Am destruction rate compared to the $\pm 1 \%$ case. It may therefore be advisable to carry out an optimisation study to determine how much axial separation is required if maximising the Am incineration rate is the objective, but the results should not be analysed in isolation, as large variations in fissile content in different parts of the assembly could have significant effects on other factors such as, as previously mentioned, material degradation. 
Figure 4 Fission and capture reaction rates in Am241 for clean Pu ( \pm 0 and $\pm 1 \%$ additional separation)

— Fission (0\% Am/Clean $20 \mathrm{GWd} / \mathrm{tHM})$ (+-0\%) - fuel_1_bottom

1.E-03

- - - - Fission (0\% Am/Clean $20 \mathrm{GWd} / \mathrm{tHM})$ (+-0\%) - fuel_6_top

— Fission (0\% Am/Clean $20 \mathrm{GWd} / \mathrm{tHM})$ (+-1\%) - fuel_1_bottom

- - - - Fission (0\% Am/Clean $20 \mathrm{GWd} / \mathrm{tHM}$ ) (+-1\%) - fuel_6_top

8.E-04

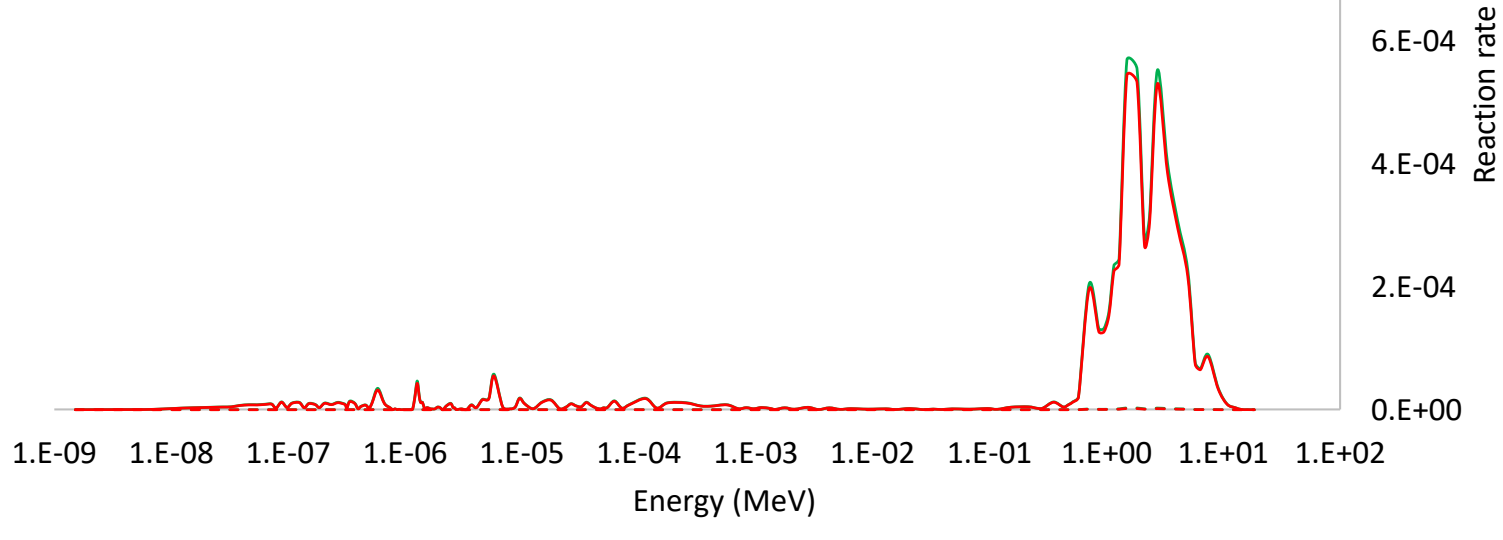

- - - - Capture (0\% Am/Clean $20 \mathrm{GWd} / \mathrm{tHM})(+-0 \%)$ - fuel 6 top

_ Capture (0\% Am/Clean $20 \mathrm{GWd} / \mathrm{tHM})$ (+-1\%) - fuel_1_bottom

- - - - Capture (0\% Am/Clean 20 GWd/tHM) (+-1\%) - fuel_6_top

8.E-03

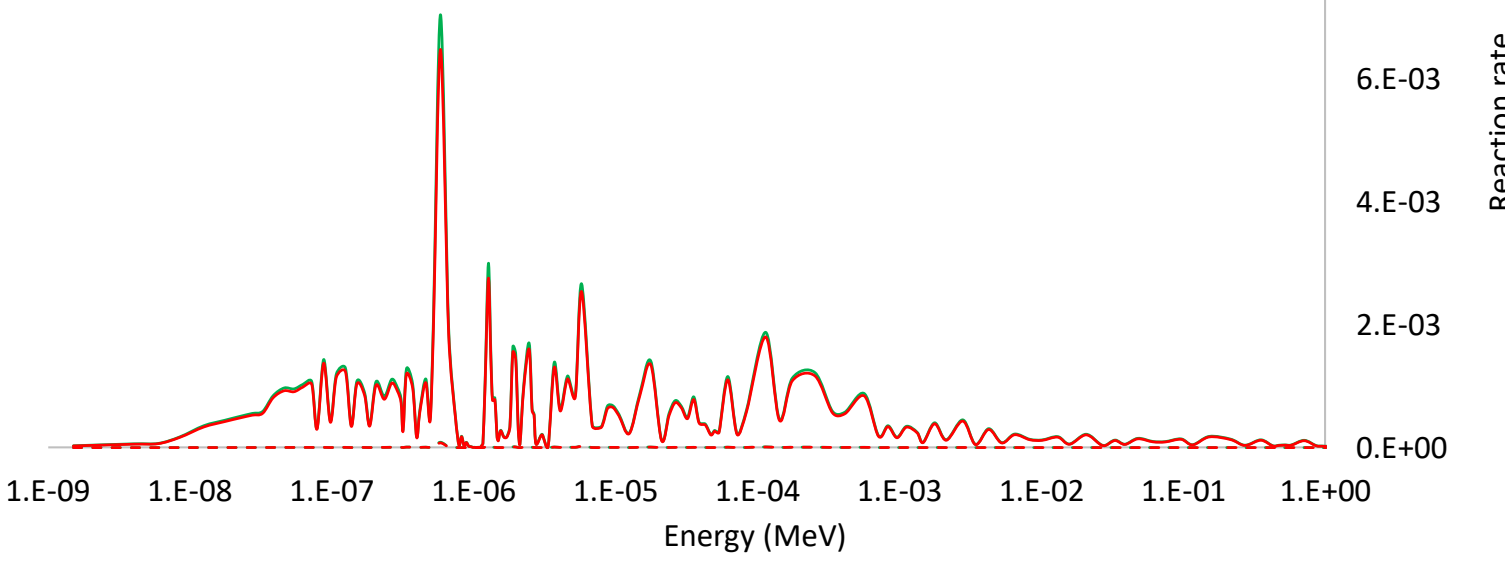


Figure 5 Axial flux profile for 'clean' Am

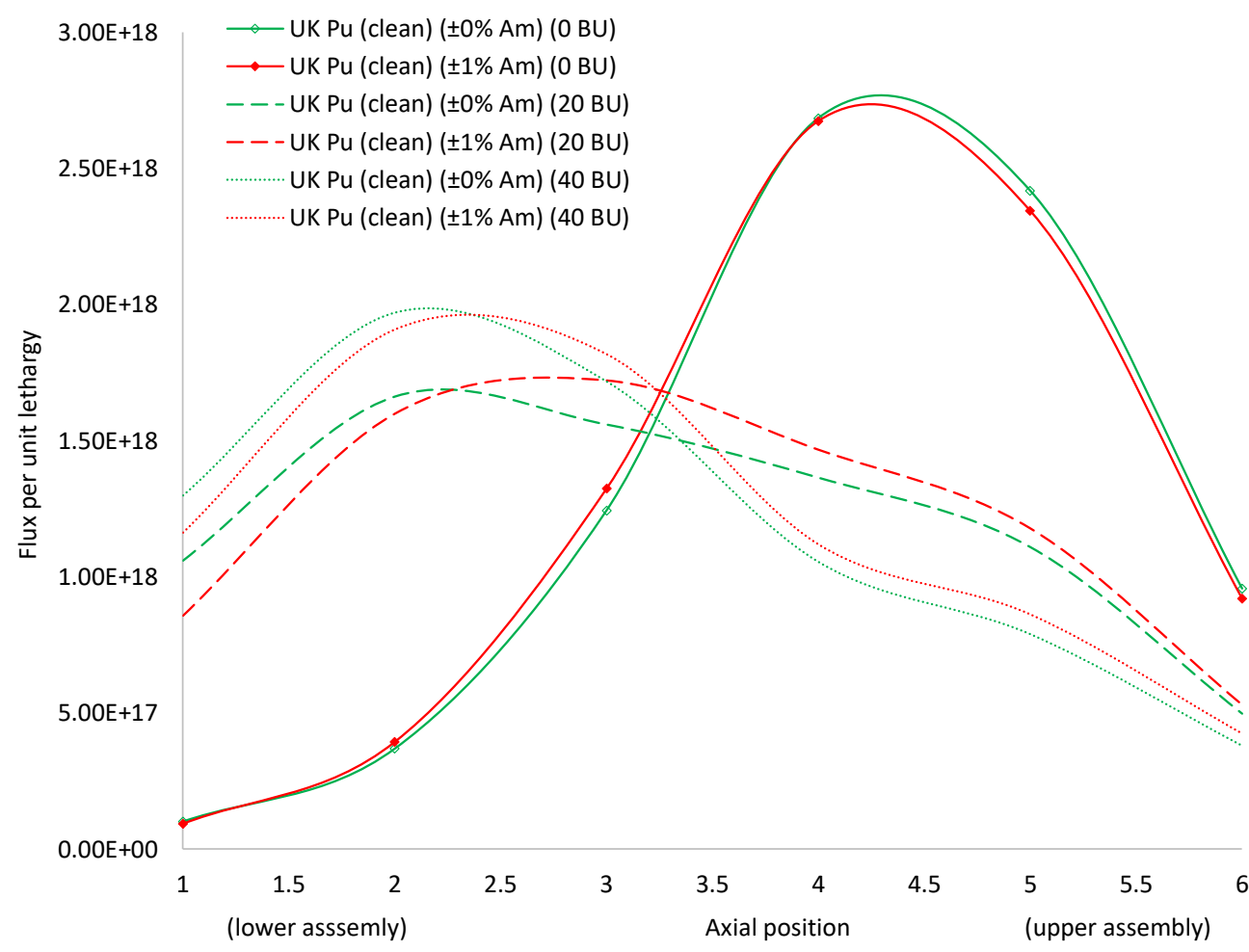

Comparing the results of this study to the PWR results reported in Part I of this paper suggested that it would be possible to load substantially more fissile material into an ABWR than a PWR and/or RMPWR (Table 6). While the PWR/RMPWR can tolerate higher Am/Pu loadings per assembly than the $A B W R$, the ABWR core will load a greater total fissile mass due to it having a greater total number of assemblies than the PWR.

It is possible to achieve higher Am destruction rates in some of the PWR/RMPWR cases, for example the VC limited case, compared to some of the ABWR options considered. However, this results in a significant reduction in Am and total Pu loading per core. It may be advisable to focus on optimising axial and radial loading patterns in ABWRs, if the recycle objective is to maximise Am incineration, such that potential reload requirements do not become prohibitively high, if a multiple recycle strategy is to later be pursued, and such that the total fissile loading is maximised, in order to reduce the stockpile as quickly as possible. 
Table 6 Maximising spatial separation of Am while maintaining negative VC (90\% VF)

\begin{tabular}{|c|c|c|c|c|c|c|c|c|c|c|c|c|c|}
\hline \multirow[t]{2}{*}{ Parameter } & \multirow[t]{2}{*}{ (\%wt) } & \multicolumn{4}{|c|}{ Clean } & \multicolumn{4}{|c|}{ As is } & \multicolumn{4}{|c|}{ Aged } \\
\hline & & $\pm 0 \%$ & $\pm 1 \%$ & $\pm 2 \%$ & $\pm 3 \%$ & $\pm 0 \%$ & $\pm 1 \%$ & $\pm 2 \%$ & $\pm 3 \%$ & $\pm 0 \%$ & $\pm 1 \%$ & $\pm 2 \%$ & $\pm 3 \%$ \\
\hline Fuel 1 (bottom) & $\mathrm{Am}$ & 18.00 & 19.00 & 20.00 & 21.00 & 15.91 & 16.91 & 17.91 & 18.91 & 15.60 & 16.60 & 17.60 & 18.60 \\
\hline $0-63.5 \mathrm{~cm}$ & $\mathrm{Pu}$ & 24.75 & 24.75 & 24.75 & 24.75 & 22.75 & 22.75 & 22.75 & 22.75 & 23.00 & 23.00 & 23.00 & 23.00 \\
\hline Fuel 2 & $\mathrm{Am}$ & 18.00 & 18.00 & 18.00 & 18.00 & 15.91 & 15.91 & 15.91 & 15.91 & 15.60 & 15.60 & 15.60 & 15.60 \\
\hline $63.5-127 \mathrm{~cm}$ & $\mathrm{Pu}$ & 24.75 & 24.75 & 24.75 & 24.75 & 22.75 & 22.75 & 22.75 & 22.75 & 23.00 & 23.00 & 23.00 & 23.00 \\
\hline Fuel 3 & $\mathrm{Am}$ & 18.00 & 17.00 & 16.00 & 15.00 & 15.91 & 14.91 & 13.91 & 12.91 & 15.60 & 14.60 & 13.60 & 12.60 \\
\hline $127-190.5 \mathrm{~cm}$ & $\mathrm{Pu}$ & 24.75 & 24.75 & 24.75 & 24.75 & 22.75 & 22.75 & 22.75 & 22.75 & 23.00 & 23.00 & 23.00 & 23.00 \\
\hline Fuel 4 & $\mathrm{Am}$ & 0.00 & 0.00 & 0.00 & 0.00 & 3.91 & 4.91 & 5.91 & 6.91 & 5.60 & 6.60 & 7.60 & 8.60 \\
\hline $190.5-254 \mathrm{~cm}$ & $\mathrm{Pu}$ & 12.00 & 12.00 & 12.00 & 12.00 & 13.75 & 13.75 & 13.75 & 13.75 & 15.00 & 15.00 & 15.00 & 15.00 \\
\hline Fuel 5 & Am & 0.00 & 0.00 & 0.00 & 0.00 & 3.91 & 3.91 & 3.91 & 3.91 & 5.60 & 5.60 & 5.60 & 5.60 \\
\hline $254-317.5 \mathrm{~cm}$ & $\mathrm{Pu}$ & 12.00 & 12.00 & 12.00 & 12.00 & 13.75 & 13.75 & 13.75 & 13.75 & 15.00 & 15.00 & 15.00 & 15.00 \\
\hline Fuel 6 (top) & $\mathrm{Am}$ & 0.00 & 0.00 & 0.00 & 0.00 & 3.91 & 2.91 & 1.91 & 0.91 & 5.60 & 4.60 & 3.60 & 2.60 \\
\hline $317.5-381 \mathrm{~cm}$ & $\mathrm{Pu}$ & 12.00 & 12.00 & 12.00 & 12.00 & 13.75 & 13.75 & 13.75 & 13.75 & 15.00 & 15.00 & 15.00 & 15.00 \\
\hline Pu loaded (kg per $1 / 3$ core) & & 8215.53 & 8215.53 & 8215.52 & 8215.51 & 8215.50 & 8215.50 & 8215.49 & 8215.48 & 8534.84 & 8534.84 & 8534.84 & 8534.82 \\
\hline Pu loaded (kg/assembly) & & 28.26 & 28.26 & 28.26 & 28.26 & 28.26 & 28.26 & 28.26 & 28.26 & 29.36 & 29.36 & 29.36 & 29.36 \\
\hline Pu burned (\%) & & 20.67 & 20.72 & 20.79 & 20.87 & 20.25 & 20.21 & 20.20 & 20.23 & 19.01 & 18.95 & 18.94 & 18.95 \\
\hline Am loaded (kg per $1 / 3$ core) & & 1141.67 & 1141.67 & 1141.67 & 1141.68 & 1060.10 & 1060.10 & 1060.11 & 1060.12 & 1128.96 & 1128.96 & 1128.97 & 1128.98 \\
\hline Am loaded (kg/assembly) & & 3.93 & 3.93 & 3.93 & 3.93 & 3.65 & 3.65 & 3.65 & 3.65 & 3.88 & 3.88 & 3.88 & 3.88 \\
\hline Am burned (\%) & & 35.38 & 34.69 & 33.78 & 32.68 & 40.53 & 40.66 & 40.41 & 39.91 & 42.20 & 42.41 & 42.28 & 41.87 \\
\hline VC $90 \%$ (BOC GWd/tHM) & & -39.25 & -38.14 & -36.96 & -35.40 & -42.97 & -39.03 & -36.52 & -34.64 & -29.77 & -25.90 & -22.95 & -21.97 \\
\hline VC $90 \%$ (EOC GWd/tHM) & & -46.13 & -46.26 & -46.37 & -46.87 & -88.77 & -89.81 & -90.47 & -91.57 & -79.79 & -80.51 & -81.97 & -83.13 \\
\hline VC 99\% (BOC GWd/tHM) & & 20.45 & 21.04 & 21.97 & 22.93 & 12.40 & 15.62 & 18.05 & 19.50 & 29.78 & 33.21 & 35.56 & 36.43 \\
\hline VC 99\% (EOC GWd/tHM) & & 2.40 & 2.11 & 1.98 & 1.26 & -45.67 & -46.79 & -47.85 & -49.09 & -35.00 & -36.25 & -37.98 & -39.42 \\
\hline Burnup (GWd/tHM) & & 40.00 & 40.00 & 40.00 & 40.00 & 40.00 & 40.00 & 40.00 & 40.00 & 40.00 & 40.00 & 40.00 & 40.00 \\
\hline keff (BOC) & & 1.117210 & 1.118590 & 1.119760 & 1.121180 & 1.092590 & 1.090560 & 1.089600 & 1.089910 & 1.077540 & 1.075310 & 1.074330 & 1.075180 \\
\hline keff (EOC) & & 1.030560 & 1.030920 & 1.030990 & 1.031120 & 1.030770 & 1.030840 & 1.030710 & 1.030690 & 1.031040 & 1.030720 & 1.030620 & 1.030290 \\
\hline
\end{tabular}




\section{Conclusions}

Part I of this study showed that, when increasing the Am content in UK Pu, the trends observed in the response of reactivity feedback coefficients were predictable, despite their sensitivity to isotopic and geometric effects on the neutron energy spectrum of the system. Results also showed that there were potential benefits to radial separation of Am in PWRs.

Part II of this study has shown that the same predictable trends in reactivity feedback coefficients as found in PWRs and RMPWRs may be expected in ABWRs, since the energy distribution of neutrons in a standard ABWR was found to lie somewhere between that of a standard PWR and the extreme case considered in the RMPWR in Part I. Therefore, it may be concluded that the presence of Am in UK Pu - in whatever quantity it happens to exist for a given batch of $\mathrm{Pu}$ - is unlikely to lead to unpredictable trends in MTC and VC with burnup.

The results of Part II have suggested that axial separation of Am241 may offer advantages in terms of maximising incineration rates, and that increased Am content may be better suited to low void fraction locations within the assembly such that transmutation of Am241 to Am242g and Am242m - and subsequent thermal fission of these isotopes - is targeted over fast fission in Am241 itself. The VC limited, full-core fissile masses were found to be significantly higher in the ABWR than the PWR/RMPWR while the incineration rates were found to be comparable.

In order to maximise chosen parameters an optimisation study should be performed for a full core. It would be advisable to consider both axial and radial separation in the ABWR, since radial separation has not been considered here and previous research appears to suggest that it may be beneficial. However, this may be computationally prohibitive using a Monte Carlo code such as Serpent. Therefore, it may be preferable to model the full core using a deterministic solver. Ideally, the neutronics solver should be coupled with a thermal-hydraulics code and the combined results analysed.

\section{Data availability statement}

To the best of the authors' knowledge, this paper and references herein contain all the data needed to reproduce and validate the results presented.

\section{Acknowledgements}

The first author is grateful for the financial support of the Engineering and Physical Sciences Research Council (EPSRC) through the Imperial College, University of Cambridge and Open University Centre for Doctoral Training in Nuclear Energy under grant EP/L015900/1ICO, Thor Energy, the Whitworth Society and the Institution of Engineering and Technology. 


\section{References}

AREVA/EDF, 2012. UK EPR Pre-Construction Safety Report: sub-chaper 14.5 (UKEPC-0002-145 Issue 08), Paris: AREVA/EDF.

Askew, J. R., Fayers, F. J. \& Kemshall, P. B., 1966. A general description of the lattice code WIMS. Journal of the British Nuclear Energy Society.

Chadwick, M. B. et al., 2006. ENDF/B-VII.0 Next Generation Evaluated Nuclear Data Library for Nuclear Science and Technology. Nuclear Data Sheets, Volume 107, pp. 2931-3060.

Erighin, M., Yin, C., Galloway, J. \& Maldonado, G. I., 2006. Analysis of BWR Lattices to Recycle Americium. Vancouver, PHYSOR.

Francois, J., Guzman, J., Martin-del-Campo, C. \& Palomera, M., 2011. Design and optimization of an equilibrium reload with MOX fuel with minor actinides. Progress in Nuclear Energy, Volume 53, pp. 566-570.

Francois, J. L. \& Guzman, R., 2007. BWR Fuel Design Using Minor Actinides as Burnable Absorber. Trans Am Nuclear Society, Volume 96, pp. 748-749.

Ganda, F., Arias, F. J., Vujic, J. \& Greenspan, E., 2012. Self-Sustaining Thorium Boiling Water Reactors. Sustainability, Volume 4, pp. 2472-2497.

Gao, L., 2014. Developing WIMS/PANTHER Model for ABWR Start-up Core. Cambridge: University of Cambridge .

GE Nuclear Energy, 1997. ABWR Design Control Document (Rev. 4), s.I.: GE Nuclear Energy.

Gill, M., 2016. The potential impact of fast reactors and fuel recycling schemes on the UK's nuclear waste inventory. Manchester: University of Manchester (PhD Thesis).

Hitachi-GE Nuclear Energy Ltd, 2017. UK ABWR Generic Design Assessment - Generic PCSR Chapter 11 : Reactor Core (GA91-9101-0101-11000 Rev.C), London: Hitachi-GE Nuclear Energy Ltd.

Humphrey, U. E. \& Khandaker, M. U., 2018. Viability of thorium-based nuclear fuel cycle for the next generation nuclear reactor: Issues and prospects. Renewable and Sustainable Energy Reviews, Volume 97, pp. 259-275.

Insulander Bjork, K., 2013. A BWR fuel assembly design for efficient use of plutonium in thoriumplutonium fuel. Progress in Nuclear Energy, Issue 65, pp. 56-63.

Insulander Bjork, K., Fhager, V. \& Demaziere, C., 2011. Comparison of thorium-based fuels with different fissile components in existing boiling water reactors. Progress in Nuclear Energy, Issue 53, pp. 618-625.

Kaltiaisenaho, T., 2014. Statistical Tests and the Underestimation of Variance in Serpent 2 (VTT-R00371-14), Espoo: VTT. 
Kim, T. K. \& Downar, T. J., 2002. Thorium fuel performance in a tight-pitch Light Water Reactor lattice. Nuclear Technology, Volume 138, pp. 17-29.

Leppanen, J. et al., 2015. The Serpent Monte Carlo code: Status, development and applications in 2013. Annals of Nuclear Energy, Issue 82, pp. 142-150.

Lindley, B. A., Franceschini, F. \& Parks, G. T., 2014c. The closed thorium-transuranic fuel cycle in reduced-moderation PWRs and BWRs. Annals of Nuclear Energy, Volume 63, pp. 241-254.

Lindley, B. A. et al., 2017. Current status of the reactor physics code WIMS and recent developments. Annals of Nuclear Energy, Volume 102, pp. 148-157.

Lindley, B. A. et al., 2014a. On the use of reduced-moderation LWRs for transuranic isotope burning in thorium fuel - I: Assembly Analysis. Nuclear Technology, Volume 185, pp. 127-146.

Lindley, B. A. et al., 2014b. On the use of reduced-moderation LWRs for transuranic isotope burning in thorium fuel - II: Core Analysis. Nuclear Technology, Volume 185, pp. 147-173.

Maldonado, G. I., Galloway, J. \& Hernandez, H., 2010. Recycling heterogeneous americium targets in a boiling water reactor. Annals of Nuclear Energy, Volume 37, pp. 256-264.

Nuclear Energy Agency Organisation for Economic Co-operation and Development, 2003. Physics of plutonium fuels: BWR MOX Benchmark - specification and results (ISBN: 92-64-19905-5), s.I.: NEA OECD.

O'Donnell, G. M., Scott, H. H. \& Meyer, R. O., 2001. A new comparative analysis of LWR fuel designs, Washington, DC : U.S. Nuclear Regulatory Commission. Division of Systems Analysis and Regulatory Effectiveness.

Palmtag, S., 2015. Initial Boiling Water Reactor (BWR) Input Specifications (CASL-U-2015-0040-000), Knoxville: U.S. Department of Energy.

Radioactive Waste Management Limited , 2016. Generic Design Assessment: Disposability Assessment for Wastes and Spent Fuel arising from Operation of the UK ABWR Part 1: Main Report (RWM TECHNICAL NOTE No. 23788023), London: Radioactive Waste Management Limited .

Raitses, G., Todosow, M., Aronson, A. \& Galperin, A., 2005. Initial Studies of Transmutation Options for Boiling Water Reactors (BNL-AFCl-2005-002), Brookhaven: Brookhaven National Laboratory.

Ramirez, J. R. et al., 2016. Analysis of actinide recycling in a Boiling Water Reactor using CASMO4/SIMULATE-3. Progress in Nuclear Energy, Volume 89, pp. 26-38.

Seifried, J. E. et al., 2015. Self-sustaining Thorium-fueled Reduced Moderation BWR Feasibility Study. Energy Procedia, Volume 71, pp. 69-77.

Wallenius, J. \& Westlen, D., 2008. Hafnium clad fuels for fast spectrum BWRs. Annals of Nuclear Energy, pp. 60-67. 